\section{Jak drzewa świadczą? W stronę nie-ludzkich figuracji świadka}

Jacek Małczyński

TEKSTY DRUGIE 2018, NR 3, S. 373-385

DOI: $10.18318 /$ td.2018.3.26
NARODOWY PROGRAM ROZWOJU HUMANISTYKI

Tekst powstał w ramach badań w projekcie Nieupamiętnione miejsca ludobójstwa i ich wpływ na pamięć zbiorowq, tożsamość kulturowq, postawy etyczne irelacje międzykulturowe we współczesnej Polsce finansowanego w ramach "Narodowego Programu Rozwoju Humanistyki" (Nr 121/NPRH 4 / $\mathrm{H}_{22} \mathrm{a} / 83 / 2016$ ).

Jacek Małczyński adiunkt w Instytucie Kulturoznawstwa UWr., członek zespołu Laboratorium $\mathrm{Hu}$ manistyki Współczesnej. Wkrótce ukaże się jego książka Krajobrazy Zagłady. Perspektywa historii środowiskowej. Współredaktor tomu Kultura nie-ludzka (2015). Obecnie interesuje się kulturowymi reprezentacjami zmian klimatycznych. Kontakt: jacek.malczynski@uwr.edu.pl

2 Wypowiedź w trakcie panelu dyskusyjnego towarzyszącego konferencji Traumatic Modernities: From Comparative Literature to Medical Humanities, Kraków, Uniwersytet Jagielloński, 21.04.2017. Zob. rozmowę S. Schuppli z Kolektywem Kuratorskim, Reframing Memory and Knowledge: The Artist as Producer, "Widok. Teorie i praktyki kultury wizualnej" 2017 nr 18, http://pismowidok.org/index.php/one/ article/view/522/1014.

3 Zob.http://susanschuppli.com/research/materialwitness/. 
nie-antropocentryczne, posthumanistyczne odmiany - warto zastanowić się, czy pojęcie świadka, które mocno jest zakorzenione w ludzkiej etyce, otwarte jest również na byty nie-ludzkie. Czy istnieją inne niż ludzkie figuracje świadka (np. rośliny, zwierzęta, rzeczy)? Kim (lub czym) staje się świadek, kiedy przestaje być człowiekiem? Kim (lub czym) staje się rzecz, roślina, zwierzę, kiedy staje się świadkiem? W jaki sposób zmieni się nasze rozumienie świadka, jeśli rozszerzymy to pojęcie na czynniki nie-ludzkie? Czy stwierdzenie, że Zagłada jest „zdarzeniem bez świadka” (Dori Laub) ${ }^{4}$ dotyczy również bytów nie-ludzkich? W artykule tym zajmuje mnie przede wszystkim drzewo jako jedna z figuracji świadka , a przedmiotem zainteresowania czynię projekt artystyczny Berlin-Birkenau Łukasza Surowca. Samo drzewo - co warto zauważyć - przyjmować może rozmaitą formę: żywej rośliny, drewna ${ }^{6}$, kory $^{7}$, metafory poetyckiej.

\section{"To drzewo było tu świadkiem"}

Projekt Berlin-Birkenau Łukasza Surowca powstał w związku z biennale sztuki w Berlinie w 2012 roku. Jedną z idei biennale, którego kuratorem był Artur Żmijewski, było podarowanie miastu czegoś, co pozostałoby w jego przestrzeni dłużej niż sama wystawa ${ }^{8}$.W tym kontekście pojawił się pomysł, aby przesadzić do Berlina brzozy rosnące w okolicy dawnego obozu w Brzezince?.

4 D. Laub Zdarzenie bezświadka: prawda, świadectwo oraz ocalenie, przeł. T. Łysak, "Teksty Drugie" $2007 \mathrm{hr} 5$.

5 Kontynuuję tym samym wątek podjęty niewcześnie w tekście: J. Małczyński Drzewa „żywe pomniki" w Muzeum-Miejscu Pamięci w Bełżcu, "Teksty Drugie” 2009 nr 1/2.

6 Np. twórczość Jana Staszaka, ludowego artysty mieszkającego w Harmężach pod Oświęcimiem, który w swej sztuce jako materiał wykorzystywał drewno drzew rosnących na terenie byłego obozu. Twórczość Staszaka omawia szczegółowo R. Sendyka Drewno i afekt. O Krzyku z Harmężów. Współczesny widok na Zagładę, w: Kultura afektu - afekty w kulturze. Humanistyka po zwrocie afektywnym, red. R. Nycz, A. Łebkowska, A. Dauksza, Wydawnictwo IBL PAN, Warszawa 2015.

7 G. Didi-Huberman Kora, przeł. T. Swoboda, Wydawnictwo w Podwórku, Gdańsk 2013.

8 Informacje na temat projektu, jeśli nie podano innego źródła, pochodzą z wywiadu przeprowadzonego przeze mnie z Łukaszem Surowcem 1 sierpnia 2014 roku w Bytomiu.

9 Mając na uwadze to, że medium, jakim posługuje się artysta, jest przede wszystkim drzewo, projekt ten można zaliczać do bio artu. Bio-artyści wykorzystują w swych pracach "mokre media" (np. rośliny, tkanki, materiał genetyczny) i za pomocą nowoczesnych biotechnologii przeprowadzają na nich różnego rodzaju eksperymenty, często eksplorując nowe formy życia. 
W sumie przesadzonych zostało ponad 300 drzew, które posadzono m.in. w parkach miejskich, przed budynkami szkół, a także w miejscach posiadających znaczenie historyczne. Na przykład kilka brzóz posadzono w pobliżu stacji kolejowej Berlin-Grunewald, z której odjeżdżały transporty Żydów do gett w Łodzi i Warszawie oraz do Auschwitz. Dzięki współpracy z organizacją ekologiczną WikiWoods 50 drzew posadzono w Volkspark Wuhlheide, gdzie w czasie wojny znajdował się obóz dla robotników przymusowych ${ }^{\mathbf{1 0}}$. Dwie brzozy posadzono również przed gmachem Kunst-Werke Institute for Contemporary Art, w którym odbywało się biennale. Nie wszystkie drzewa trafiły jednak do Berlina. Na przykład, jedną z brzóz posadzono w Krakowie przed budynkiem MOCAK-u. Drzewa z Birkenau trafiły również do byłego obozu koncentracyjnego w Bergen-Belsen. W każdym z tych miejsc umieszczona została tabliczka informująca o tym, skąd pochodzą drzewa. Akcje sadzenia drzew miały zazwyczaj charakter uroczystości z udziałem artysty.

Surowiec po raz pierwszy wybrał się do Brzezinki zimą 2011 roku. Podczas następnej wizyty, wczesną wiosną, wykopał z lasu rosnącego w okolicy obozu około 400 młodych brzóz. Drzewa te zostały najpierw przesadzone do rodzinnego ogrodu artysty położonego pod Rzeszowem. Zabieg ten miał na celu ich wzmocnienie przed transportem do Berlina. Obawiano się bowiem, że młode drzewa żyjące w leśnym środowisku, mogą nie przyjąć się w przestrzeni miasta. Jak mówił artysta: „Te drzewa mają niesamowity symboliczny potencjał. Nie mogłem ich tu przywieźć i pozwolić żeby umarły. To by prowadziło do mylnych interpretacji"11. Jesienią drzewa zostały przewiezione do Berlina, gdzie znalazły się pod opieką zawodowego ogrodnika. Kilkanaście słabszych, zbyt młodych, karłowatych brzóz pozostało w ogrodzie artysty.

Drugi etap (przełom kwietnia i maja 2011 roku) polegał na zebraniu w lesie w Brzezince nasion brzóz. Po wysuszeniu zostały one wysłane do

Sztuka biologiczna podejmuje często temat relacji między roślinami a ludźmi. Pokazuje również, w jaki sposób rośliny komunikują się, poruszają i pamiętają. Podejmuje kwestię godności roślin oraz troski o nie. Zob. M. Bakke Bio-transfiguracje. Sztuka i estetyka posthumanizmu, Wydawnictwo Naukowe UAM, Poznań 2010. Biorąc na warsztat "mokre media", artyści biorą na siebie szczególny rodzaj odpowiedzialności za efekty swej pracy. W tym kontekście nasuwa się ogólne pytanie, czy bio-art jest stosowny do „przedstawiania” Zagłady?

WikiWoods jest stowarzyszeniem działającym na rzecz zwiększenia świadomości społecznej na temat zagrożeń związanych ze środowiskiem. Działalność WikiWoods polega m.in. na organizowaniu akcji sadzenia drzew. 
Berlina, gdzie zajął się nimi artysta-ogrodnik Igor Vucic, który wyhodował z nich młode pędy. W sumie wyhodowano 2000 sadzonek. Rośliny zostały umieszczone w małych, plastikowych doniczkach o wymiarach $10 \mathrm{x} 10 \mathrm{~cm}$ i były wystawione w specjalnie zaaranżowanej w tym celu sali galerii, która przypominała laboratorium: sadzonki były rozłożone na kilku wielkich stołach pod sztucznym oświetleniem. Odwiedzający wystawę mogli zabierać ze sobą sadzonki. W zamian za to otrzymywali specjalny certyfikat, na którym napisano:

Ta sadzonka wyrosła wiosną 2012 roku z nasion z lasu brzozowego z terenu byłego obozu koncentracyjnego Auschwitz-Birkenau, gdzie miliony ludzi były więzione i zamordowane przez nazistowski reżim. Jest to żywy fragment pamięci, naturalne archiwum, które opowiada o cierpieniu i niezliczonych śmierciach w obozie. Ten dokument potwierdza autentyczność sadzonki, a także zobowiązanie okaziciela do opieki nad rośliną ${ }^{12}$.

Podczas Biennale w sali galerii wyświetlano ponadto dwa filmy stanowiące dokumentację projektu. Pierwszy z nich, trwający niecałe 10 minut, przedstawia akcję wykopywania drzew z lasu w Brzezince oraz ich sadzenie w Berlinie. Film ten składa się z dwóch części ${ }^{13}$. Pierwsza została nakręcona wczesną wiosną. Niebo jest tu zachmurzone, drzewa nie mają jeszcze na sobie liści, w tle słychać śpiew ptaków. W filmie występuje mieszkaniec Brzezinki, który pomagał artyście wykopywać drzewa. Widzimy, jak mężczyzna za pomocą łopaty wykopuje młode brzozy, otrząsa ich korzenie z ziemi i znosi drzewa w jedno miejsce. Odgrywa on także rolę przewodnika, który opowiada historię. Do jego rodziny należał przed wojną tak zwany „biały domek”, w którym Niemcy uruchomili pierwszą komorę gazową. Wskazując to miejsce, mówi: „To musiała być solidna chałupa [...] 1200 osób - tak książka podaje - że tu wchodziło. 1200 osób". Komentuje on również wysokość i grubość brzóz, które mają według niego świadczyć o tym, że wyrosły one na prochach ludzkich. Mężczyzna mówi, że pamięta z dzieciństwa, jak były one jeszcze młode. Wskazując na jedno z nich mówi: „To drzewo było tu świadkiem”. Druga część filmu przedstawia transport brzóz oraz akcje ich sadzenia w różnych punktach Berlina.

12

13

Tłum. J. Małczyński

Film dostępny on-line: https://artmuseum.pl/pl/filmoteka/praca/surowiec-lukasz-berlin-birkenau (27.05.2018). 
Drugi z filmów, trwający ponad 5 minut, dokumentuje zbieranie nasion. W filmie tym nie występuje sam Surowiec. Zamiast niego pojawia się artysta-performer, który - ubrany w białą, luźną, marynarkę i słomiany kapelusz - przypomina swym wyglądem ogrodnika. Film został nakręcony latem. Tym razem niebo jest bezchmurne, słychać dźwięki owadów. Początkowo nic nie wskazuje na to, że znajdujemy się w Brzezince. Film zaczyna się od ujęcia poruszającej się na wietrze gałęzi brzozy. Po chwili na obrazie pojawia się ręka, a następnie wyłania się cała sylwetka mężczyzny, który zbiera nasiona drzewa i umieszcza je w szklanym pojemniku. Kolejne ujęcie przedstawia staw odbijający niewyraźnie dwa pnie brzóz oraz postać mężczyzny. W kolejnych scenach ze słoikiem w ręku i plecakiem na ramieniu przechadza się on po pokrytej zieloną trawą bujnej łące i lesie. W oddali można usłyszeć szczekanie psa. Następne zdjęcia stopniowo ujawniają, że film został nakręcony w Birkenau. Początkowo w tle zaczynają rysować się poobozowe, czerwone budynki, wieża strażnicza oraz słupy ogrodzeniowe. W kolejnym ujęciu widzimy charakterystyczne ogrodzenie z drutu kolczastego. Po chwili znów jesteśmy w lesie. Przez chwilę przed kamerą przefruwają motyle i pszczoła. Jedno ze zdjęć przedstawia panoramiczny widok obozu z rozłożystym drzewem w środku planu. Na koniec mężczyzna przesypuje zebrane nasiona ze słoika do kartonu. Przedstawiając na pół dziki, porośnięty bujną, kolorową roślinnością krajobraz, Surowiec - podobnie jak Mirosław Bałka w Winterreise - pokazuje, że miejsce dawnego obozu pogrążone jest w spokoju, żyje własnym życiem. Natura, nie zważając na to, co się tu wydarzyło, nieustannie, cyklicznie odradza się.

Jak tłumaczył Surowiec, pomysł przesadzenia drzew z Birkenau do Berlina wziął się ze świadomości ograniczeń wynikających z tradycyjnej, monumentalnej rzeźby pomnikowej: „Kamienie są martwe. Nie są dobrym medium pamięci. Natomiast rośliny są. Rośliny są żywe, mają naturalny cykl i potrzebują opieki..."14. Jego zdaniem natura jest medium, które lepiej sprzyja pracy pamięci niż kamienny pomnik:

kamień nie jest dobrym medium dla pamiętania. Jest lepszy dla zapominania. Tak samo jest z brązem. Chcę dać ludziom możliwość aktywnego zaangażowania w pamiętanie przeszłości. Pomnik w tym nie pomaga. Pomniki są w pewnym sensie wizualną przemocą, narzuconą przez władze. Ludzie, którzy włączyli się w mój projekt, zrobili to z własnej woli.

Łukasz Surowiec w rozmowie z Danielem Millerem. 
Zasadzenie drzewa jest dla nich osobistym kontaktem z pamięcią. Te, wydawałoby się, niewinne rośliny mają potencjał organizowania historii. Będą rosły w Berlinie już zawsze. ${ }^{15}$

W tym kontekście projekt Berlin-Birkenau można zatem interpretować jako przykład „kontrpomnika”. Tradycyjne pomniki stawiane są zazwyczaj (lub obalane) przez zwycięzców, przedstawiają ich wizję historii, w tym sensie stanowią przejaw „przemocy wizualnej”, o której wspomina Surowiec. Wraz z upływem czasu stają się one jednak niewidoczne, wtapiają się w krajobraz i sprawiają, że przeszłość zastyga w bezruchu, a przechodnie zaczynają mijać je obojętnie. Pomniki, jak twierdzi James E. Young, ,ignorują naturalną zmienność wszystkich przedmiotów kultury materialnej"16.

\section{Jak społeczeństwa pamiętają}

Artysta, wykorzystując jako medium drzewo, zwrócił uwagę na performatywny wymiar pamięci, na to „jak społeczeństwa pamiętają", by przywołać tytuł klasycznej pracy Paula Connertona ${ }^{17}$. Podkreśla znaczenie indywidualnego, wynikającego z własnej woli kontaktu z przeszłością. Osoby, które zdecydowały się zabrać ze sobą z galerii sadzonki brzóz, pielęgnując rośliny, będą zarazem pielęgnowały własną pamięć o Zagładzie. Z czasem jednak, po przesadzeniu do ziemi, drzewa te zaczną żyć własnym życiem i nie wymagają już dalszej opieki. Z drugiej strony akcję przesadzenia drzew z Birkenau do Berlina można traktować jako rodzaj „przemocy wizualnej”, próbę narzucenia pewnej interpretacji historii, która prowadzić może do różnego rodzaju konfliktów związanych z pamięcią.

Jak wspominałem, przesadzenie drzew z Birkenau do Berlina miało na celu podarowanie miastu czegoś, co pozostanie w jego przestrzeni dłużej niż sama wystawa. Performans ten miał również znaczenie ideologiczne. Według artysty, przesadzając drzewa z Birkenau do Berlina, zwraca się Niemcom ich „dziedzictwo narodowe":

15 Tamże.

16 J.E. Young, Pamięć i kontrpamieć. W poszukiwaniu społecznej estetyki pomników Holocaustu, przeł. G. Dąbrowski, "Literatura na Świecie” 2004 nr 1/2, s. 272.

17 P. Connerton/ak społeczeństwa pamiętają, przeł. M. Napiórkowski, Wydawnictwa UW, Warszawa 2012. 
To ich dziedzictwo. To część naszej historii, ale to nie my wybudowaliśmy te obozy. Być może nie jest to najbardziej palący problem w tej chwili, ale to ważne dla Polaków, żeby przekazać je w niemieckie ręce. Mamy własne cmentarze, za które jesteśmy odpowiedzialni. A ponieważ ciąży na nas odpowiedzialność dbania o miejsca Holokaustu, trudno nam rozmawiać o własnej historii, naszych czynach. Kiedy nie będziemy musieli się zajmować obozami koncentracyjnymi, będziemy mogli zacząć [...] przepracowywanie własnych problemów i historii, i złych rzeczy, które zrobiliśmy. Uważam, że należy się podzielić odpowiedzialnością i oddać każde miejsce pamięci narodowi, który jest odpowiedzialny za to, co się tam wydarzyło. ${ }^{18}$

W tym sensie projekt Berlin-Birkenau ma podtekst polityczny i wpisuje się we wciąż żywe dyskusje dotyczące odpowiedzialności Niemców za Zagładę (a także współodpowiedzialności Polaków). Pracę Surowca można zatem traktować jako rodzaj interwencji w społeczne ramy pamięci (i niepamięci) o Zagładzie. Przesadzając brzozy z Birkenau do Berlina, artysta przypomina Niemcom o tym, że Holocaust stanowi część ich historii i to oni ponoszą winę za to, co wydarzyło się w obozach śmierci. Z tego właśnie powodu, przez analogię do nazwy obozu Auschwitz-Birkenau, projekt został nazwany Berlin-Birkenau. Problem pamięci łączy się tu z kwestią tożsamości zbiorowej. Przesadzanie drzew uruchamia całą serię skojarzeń związanych z zakorzenianiem się oraz poszukiwaniem tożsamości. Symbolikę tę wykorzystywali m.in. naziści w polityce Dauerwald. Jak twierdził Hermann Göring, który w 1934 roku mianował się Inspektorem Rzeszy ds. Lasów, „odwieczny las i odwieczny naród są ideami nierozerwalnie ze sobą związanymi" ${ }^{\text {"19 }}$. Stosunek nazistów do

Łukasz Surowiec w rozmowie z Danielem Millerem.

M. Imort "Eternal Forest - Eternal Volk". The Rhetoric and Reality of National Socialist Forest Policy, w: How Green Were the Nazis? Nature, Environment and Nation in the Third Reich, ed. by F.J. Brüggemeier, M. Cioc, T. Zeller, Ohio University Press, Athens, Ohio 2005, s. 54. Jak zauważa Imort, prowadzona przez nazistów „polityka leśna” w wielu kwestiach wyprzedzała postulaty stawiane przez współczesną ekologię: „Organiczny sposób widzenia natury, który leżał u podstaw modelu Dauerwald, w dużym stopniu przypomina to, co dziś nazwalibyśmy holizmem, enwironmentalizmem, zrównoważonym rozwojem, bioróżnorodnością, ochroną środowiska czy zarządzaniem ekologicznym" (s. 45). Niektóre z ustanowionych przez nazistów regulacji przetrwały zresztą w Niemczech w niezmienionej postaci po wojnie. O podejmowanych przez Göringa, zapalonego myśliwego, próbach germanizacji Puszczy Białowieskiej pisze Simon Schama. Zob. T. Rolke (fot.), S. Schama (tekst) Tu byliśmy. Ostatnie ślady zaginionej kultury, przeł. B. Rymaniak, edition.fotoTAPETA, Berlin, Warszawa 2008, s. 166-174 (wyd. org. S. Schama Landscape and Memory, Fontana Press, London 1996, s. 70-74). 
drzew opierał się w dużej mierze na ideologii rasistowskiej. Zgodnie z prowadzoną polityką niemieckie lasy miały być oczyszczone z wszelkich obcych gatunków drzew. Społeczeństwo natomiast, podobnie jak las, miało stanowić organiczną całośćc ${ }^{20}$.

Przesadzając drzewa z Birkenau do Berlina pod hasłem przywrócenia Niemcom ich „dziedzictwa narodowego”, artysta włącza się w dyskusję na temat „niemieckiej winy”, uruchamia jednak tym samym imaginarium, do którego odwołują się dyskursy nacjonalistyczne. Warto zastanowić się również, czy artyście przysługiwało prawo do przesadzania drzew. Kwestia ta wiąże się z pytaniem o to, do kogo należą brzozy z lasu w Birkenau. Twierdząc, że poprzez gest przesadzenia drzew przywraca się Niemcom ich „dziedzictwo narodowe", zakłada się, że rośliny te są ich własnością, co wcale nie jest oczywiste. Sam Surowiec zwraca uwagę na to, że drzewa te wyrosły na ludzkich prochach. Jak mówi: „Drzewa w Birkenau piją wodę z ziemi zmieszanej z prochami i oddychają tym samym powietrzem, w którym unosił się dym ze spalonych ciał. W tych drzewach jest coś z tamtych ludzi"21. Przyjmując taki organiczny punkt widzenia, można zatem powiedzieć, iż drzewa te stanowią własność ofiar. Tak zresztą postrzega się drzewa w judaizmie. Zgodnie z tradycją żydowską drzewa rosnące na cmentarzu przynależą do zmarłych ${ }^{22}$. Z tego powodu nie wolno ich wycinać, podobnie jak nie powinno się wynosić poza teren cmentarza opadłych liści i gałęzi. Gdyby przyjąć psychoanalityczny punkt widzenia, można by zaryzykować stwierdzenie, że cała akcja jest

20 Drzewa odgrywają również istotną rolę w konflikcie palestyńsko-izraelskim. Palestyńczycy postrzegają drzewa jako świadectwo ich prawa do ziemi. Dyskurs nacjonalistyczny obfituje w przedstawienia Palestyny jako sielskiego, rolniczego kraju, a drzewa traktowane są jako świadkowie narodowej historii. Palestyńczycy szczególne znaczenie przypisują drzewom oliwnym. Z tego powodu wojska izraelskie wycinały oliwki na zajętych przez siebie terytoriach. Współcześnie drzewa oliwne symbolizują miejsca po zniszczonych, palestyńskich wioskach. Drzewa odgrywały również ważną rolę w konstruowaniu tożsamości zbiorowej Izraelczyków. Od początku XX wieku organizacje syjonistyczne prowadziły akcje sadzenia drzew mające symbolizować zakorzenienia w Ziemi Świętej. Drzewa sadzi się również z okazji święta Tu Bishvat, podczas którego Żydzi w diasporze spożywali owoce pochodzące z Izraela i recytowali poświęcone im fragmenty Biblii. Pełnią one ponadto istotną funkcję w Yad Vashem, gdzie stanowią symbol sprawiedliwych wśród narodów świata. Zob. C. Bardenstein Trees, Forests, and the Shaping of Palestinian and Israeli Collective Memory, w: Acts of Memory. Cultural Recall in the Present, ed. by M. Bal, J. Crewe, L. Spitzer, Dartmouth College, University Press of New England, Hannover-London 1999, S. 148-167.

Łukasz Surowiec w rozmowie z Danielem Millerem.

Życia nie starczy. Z Aleksandrem Wąsowiczem rozmawia Piotr Paziński, „Midrasz” 2007 nr 4, s. 7. 
przykładem „rozgrywania w działaniu”, które J. Laplanche i J.-B. Pontalis za Freudem zdefiniowali jako „działanie, przez które podmiot pozostający pod wpływem swych pragnień i nieświadomych fantazji, przeżywa je w teraźniejszości, z poczuciem ich aktualności tym żywszym, że nie rozpoznaje on ich źródła ani powtarzalnego charakteru"23. Idąc tym tropem, można dojść do wniosku, iż przesadzając drzewa z powrotem do Berlina, w sferze symbolicznej artysta rozgrywa historię znaną skądinąd i wydaje na powrót „ofiary” w ręce „oprawców”. Należy wspomnieć w tym miejscu, że brzozy z Birkenau kilkakrotnie były atakowane przez członków neonazistowskiej Narodowodemokratycznej Partii Niemiec.

\section{Jak drzewa świadczą}

Performatywny, afektywny i last but not least symboliczny potencjał projektu Berlin-Birkenau Łukasza Surowca bierze się ze szczególnej relacji w stosunku do przeszłości i miejsca, z którego pochodzą drzewa. Aby zrozumieć, jak drzewa pamiętają, warto sięgnąć do książki antropologa Eduardo Kohna zatytułowanej Jak myśla lasy. W stronę antropologii poza-ludzkiej ${ }^{24}$. Praca ta stanowi studium indiańskiego plemienia Keczua. Kohn stawia w niej tezę, że nie tylko ludzie, lecz również inne istoty żywe posługują się znakami. Nawiązując do teorii Charlesa S. Peirce'a, dowodzi on, że klasyczna antropologia uprzywilejowuje opierający się na konwencji symbol kosztem innych, bardziej „naturalnych" rodzajów znaków ${ }^{25}$. Podczas gdy symbol jest specyficznie ludzką odmianą znaku, inne istoty żywe komunikują się za pomocą ikon oraz indeksów. Jak długo myślimy o znakach wyłącznie jako o symbolach, tak

23 J. Laplanche, J.-B. Pontalis Słownik psychoanalizy, przeł. E. Modzelewska, E. Wojciechowska, Wydawnictwa Szkolne i Pedagogiczne, Warszawa 1996, s. 291. Kwestię tę szczegółowo omawia D. LaCapra Psychoanaliza, pamięć i zwrot etyczny, przeł. M. Zapędowska, w: Pamięć, etyka, historia. Anglo-amerykańska teoria historiografii lat dziewięćdziesiątych (Antologia przekładów), red. E. Domańska, Wydawnictwo Poznańskie, Poznań 2002.

24 E. Kohn How Forests Think. Toward an Anthropology Beyond the Human, University of California Press, Berkeley-Los Angeles-London 2013. Książka ta została żywo przyjęta. Wśród jej recenzentów był m.in. Bruno Latour, który zauważył, że koncepcja Kohna odnosi sukces tam, gdzie zawodzi teoria aktora-sieci. B. Latour Ourselves, forms and forces, „HAU: Journal of Ethnographic Theory" 2014 No. 4 (2).

25 Wątki te podejmuje H. Michalczyk, Przeciw antropocentryzmowi. Zagadnienie komunikacji na tle Peirce'owskiego rozumienia semiozy, "Studia Kulturoznawcze” 2015 nr 1. Autorka podkreśla, że Peirce w swej koncepcji znaku unikał odniesień do człowieka. 
długo nie jesteśmy w stanie zrozumieć tego, jak myślą, pamiętają i świadczą drzewa. Zdolność do reprezentowania świata, zdaniem Kohna, nie jest zatem wyłącznie ludzkim atrybutem, lecz cechą wszystkich żywych organizmów: „Nieludzkie formy życia również reprezentują świat. To bardziej rozległe rozumienie reprezentacji jest trudne do dostrzeżenia ponieważ nasza teoria społeczna - humanistyczna czy posthumanistyczna, strukturalistyczna czy poststrukturalistyczna - łączy reprezentację z językiem"26. W tym kontekście nie dziwią liczne u Kohna odwołania do prac Gilles'a Deleuze’a i Félixa Guatarriego, Donny Harraway czy Bruno Latoura. Jak deklaruje Kohn:

W How Forest Think zamierzam wesprzeć posthumanistyczne krytyki tego, w jaki sposób traktowaliśmy ludzi jako wyjątkowych - i w ten sposób zasadniczo oddzielonych od reszty świata - poprzez rozwinięcie bardziej zdecydowanego badania zrozumienia relacji między ludźmi i istotami nieludzkimi. Czynię to, rozważając, co może znaczyć stwierdzenie, iż lasy myślą; przepracowując powiązania między procesami reprezentacji i procesami życiowymi. ${ }^{27}$

„Myślące lasy” prowokują zatem do otwarcia ludzkiego świata. Takie przeorientowanie antropologii wymaga jednak przemyślenia dotychczas stosowanych w niej koncepcji, metod i narzędzi poznawczych.

Podobnie jak Kohn, Deborah Bird Rose i Thom van Dooren w artykule Encountering a More-Than-Human World. Ethos and the arts of witness postuluja troskę w stosunku do różnych form życia składających się na nasz świat. „Nasze podejście - piszą - jest zakorzenione w etycznej praktyce «stawania się świadkiem», która stara się badać i odpowiadać innym w pełni ich szczególnego «ethosu» lub sposobu życia"28. Etos autorzy rozumieją za Cliffordem Geertzem jako „ton, charakter i jakość życia, jakie wiodą tworzący go ludzie, jego moralny i estetyczny nastrój i styl; jest to główna postawa człowieka wobec siebie i świata, która znajduje swe odbicie w kształcie ludzkiego życia"29.

26 E. Kohn, How Forests Think..., s. 8.

27 Tamże, s. 7.

28 D.B. Rose, T. van Dooren Encountering a More-Than-Human World. Ethos and the arts of witness, w: The Routledge Companion to the Enviromental Humanities, ed. by U.K. Heise, J. Christensen, M, Niemann, Routledge, London 2017, s. 120.

29 Tamże, s. 121. C. Geertz Interpretacja kultur. Wybrane eseje, przeł. M.M. Piechaczek, Wydawnictwo UJ, Kraków 2005, s. 151. 
Rose i van Dooren rozszerzają jednak to pojęcie również na byty nie-ludzkie, posiadające swój własny „kognitywny i behawioralny styl” odróżniający je od innych. Jak przypominają, za Donną Haraway, „być oznacza stawać się z innymi". Etosy nigdy nie powstają w izolacji, są emergentne, zawsze istnieją w relacjach. W,więcej-niż-ludzkim świecie” komunikacja nie jest wyłącznie ludzkim atrybutem. „Świadczyć oznacza uczestniczyć w świecie w jego relacyjnym stawaniu się"30.

\section{Poststricptum}

Podczas gdy koncepcja projektu Łukasza Surowca odnosi się przede wszystkim do kwestii związanych z pamięcią zbiorową, niemniej interesujący od jej wymiaru symbolicznego jest aspekt ekologiczny. Parafrazując tytuł książki Kohna i przyjmując nie-antropocentryczny punkt widzenia, można prowokacyjnie zapytać: „Co o tym wszystkim «myślą» drzewa?” (lub: „Jak drzewa pamiętają?”). Czy w ich interesie jest zmiana środowiska, w jakim żyły? W jaki sposób las, w którym żyły zareagował na tę zmianę? Przypomnę, że zanim brzozy zostały przesadzone do Berlina, trafiły do rodzinnego ogrodu artysty, ponieważ istniało ryzyko, że żyjące dotychczas w lesie młode drzewa nie przyjmą się w środowisku miejskim. Już w czasie przesadzania, a później transportu, kilkanaście drzew zostało uszkodzonych i w wyniku tego uschło. Kilka innych drzew stało się ofiarą neonazistów, a sadzonki, które pozostały po wystawie trafiły na śmietnik. Aspekt ekologiczny staje się bardziej widoczny, jeśli weźmie się pod uwagę dalsze losy projektu. Jesienią 2013 roku Surowiec zaprezentował swą pracę w Hong Kong City Hall. Tym razem artysta nie przesadzał drzew, lecz zawiózł do Honk Kongu sadzonki wyhodowane z nasion zebranych w Brzezince. Podobnie jak w przypadku berlińskiego biennale, odwiedzający wystawę mogli zabierać ze sobą młode rośliny. Na taki gest zdecydowało się ok. 200 osób. Nie wiadomo jednak, jak dorosłe brzozy będą zachowywać się w klimacie zwrotnikowym. Już w czasie wystawy okazało się, że ich pędy rosną bardzo szybko. Ponadto, ze względu na łagodną zimę (średnia temperatura wynosi ok. 17 stopni), drzewa te prawdopodobnie nie będą zrzucać liści.

Swoiste post scriptum do projektu Berlin-Birkenau stanowiła praca Sterben und Sterben zaprezentowana przez Surowca w 2013 roku w Muzeum Sztuki Nowoczesnej w Warszawie. Składa się ona z uschniętej brzozy, która - niczym 
„martwa natura” - została umieszczona za szybą i oprawiona w ramę. Brzoza ta jest jednym z drzew, które nie przetrwało podróży z Birkenau do Berlina. W ten sposób artysta pokazał niezamierzony efekt swej pracy, a także ryzyko, jakie podejmuje się, czyniąc z drzewa medium sztuki i powołując je do bycia świadkiem. Jak mówił Surowiec o Berlin-Birkenau:

To jest praca o tym, co ludzie mogą zrobić. O naszych destrukcyjnych możliwościach. Te drzewa przypominają o tym, że wydarzyło się coś bardzo złego. I jeśli o tym zapomnimy, to może się to zdarzyć jeszcze raz. W tej pracy jest szacunek dla ludzi, którzy umarli. I wydaje mi się, że ci, którzy stracili życie w Auschwitz, woleliby być pamiętani w ten sposób - poprzez żywe drzewo, a nie martwy kamień. ${ }^{31}$

Czy nie jest jednak tak, że projekt Berlin-Birkenau paradoksalnie pokazuje inne „destrukcyjne możliwości” drzemiące w człowieku, jego instrumentalny stosunek do przyrody? Akt przesadzenia drzew z Brzezinki do Berlina można interpretować jako przejaw przemocy człowieka w stosunku do przyrody. Jak zauważył Martin Jay, , sztuka ogrodowa” jest nierozerwalnie związana z przemoca, nigdy nie pozostaje niewinna, pozostawia brud pod paznokciami lub pęcherze na rękach ${ }^{32}$. Warto zastanowić się zatem, czy artysta w wyniku całej akcji nie pobrudził sobie przypadkiem rąk?

Łukasz Surowiec w rozmowie z Danielem Millerem. 


\section{Abstract}

\section{Jacek Małczyński}

UNIVERSITY OF WROCŁAW

How Do Trees Testify? Towards Non-Human Witness Figurations

Małczyński explores the question whether the concept of the witness, rooted in human ethics, can be extended to non-human beings (e.g. plants, animals, objects). While his main focus is on the tree as a figuration of the witness, the subject of interpretation is Łukasz Surowiec's artistic project Berlin-Birkenau (2012). Referring to Eduardo Kohn's book How Forests Think (2013) and the extended concept of semiosis, Małczyński argues that trees testify to the past in an index-like manner. He also draws attention to the project's environmental consequences.

\section{Keywords}

Holocaust, environmental history, witness, memory, Łukasz Surowiec, Berlin-Birkenau, Auschwitz-Birkenau 